Final Version published as: Slater, A. (2014) 'Wearing in memory-materiality and oral histories of dress', Critical Studies in Fashion and Beauty, Vol. 5, No. 1, pp. 125-139. DOI: 10.1386/csfb.5.1.125_1. (C) Intellect.

\title{
Wearing in memory: materiality and oral histories of dress
}

\author{
Dr Alison Slater
}

Manchester Metropolitan University

Keywords: dress, identity, materiality, memory, oral history, Second World War

\begin{abstract}
This article considers materiality in relation to memories of dress and explores why women remember the materiality of clothes they no longer wear or even no longer own. The focus is on two historical case studies of specific garments collected through primary interviews undertaken as part of my doctoral research (Slater 2011). One, a black silk-velvet dress, belonged to Mary who had kept the skirt of the garment, with its signs of wear and physical material traces of use. It was bound up with memories of her late brother, who paid for the dress before his death on active service in the Second World War, and her late husband and their early lives together. Doris' sister made the other dress for her twenty-first birthday in 1942. Doris had not kept this cotton-organdie dress, but this decision was full of regret. In her case, retaining memories of the materiality of the garment and the occasion when it was first worn had become a substitute for the garment itself. Both oral histories reveal the significance of materiality at the time a garment is worn and in how dress wears in and on our memories.
\end{abstract}

\section{Introduction}

It is widely accepted that materials are important in dress histories (Weiner and Schneider, 1989); however, there has been a tendency for studies of dress to focus on elements such as production and consumption without recognising the relation of materials to the material garments themselves. It is only recently that researchers have begun to bring these elements together and explore materiality as central to our experiences and understandings of clothing and its historical, social and cultural contexts (see Taylor 2002; Woodward 2002; Norris 2005; Woodward 2007). As Sophie Woodward (2002) asserted, in a review of the series of Dress, Body and Culture books published by Berg, a 'lack of engagement with the physicality of clothing itself' means that garments remain 'a ghostly presence, coming to appear immaterial' (Woodward 2002: 346).

In a special 'Materiality' edition of Archaeological Dialogues in 2007, Tim Ingold explained that we are 'immersed' in materials, as material objects are all around us, but we 'transform' materials through construction, acquisition and use. As a result, materials are in a constant state of 'flux' and the 
Final Version published as: Slater, A. (2014) 'Wearing in memory-materiality and oral histories of dress', Critical Studies in Fashion and Beauty, Vol. 5, No. 1, pp. 125-139. DOI: 10.1386/csfb.5.1.125_1. (C) Intellect.

materiality of things changes over time (Ingold 2007: 7). Ingold's ideas about materiality seem particularly applicable to dress histories, as the materials of clothing change and transform as they become garments, and the subsequent wearing down of the materials. David Pye (1968) differentiated between the 'properties' and 'qualities' of materials, highlighting that while 'material properties' are objectively measurable, the subjective experience of 'material qualities' 'are ideas of ours' and form part of an individual's 'private view of the world' (Pye 1995 [1968]: 88). When extended to ideas about materiality, defined here as the 'aspect or character' of a physical material object (OED 2014 [online]), Pye's ideas highlight that interpretations of materiality incorporate personal values and preferences as well as the properties and qualities of material objects.

In an attempt to centralise the 'physicality of clothing' (Woodward 2002: 346) and 'take materials seriously' (Ingold 2007: 14), this article considers the materiality of two garments from the early 1940s, using oral evidence gathered through sound-recorded interviews in 2009 as part of my doctoral research into working-class dress in the Second World War (Slater 2011). Following Trevor Lummis (1987: 26-27), the term 'oral evidence' is used to define the words spoken and recorded through the interview process and 'oral history' defines the interpretation of oral evidence against the wider context of an individual's life.

Recognising the 'self' as a dynamic enterprise (Giddens 1991), this article will develop Maura Banim and Ali Guy's (2001: 206) notions that retained clothing that is no longer worn represents 'continuing', 'discontinued' and 'transitional' identities. The focus in this article is how the materiality of clothing worn at a specific time is discussed in self-reflexive narratives that seek to explain the relationships between memories of specific events, relationships with others and past and current life stages, in the context of the changing self. Psychological theories about memory are used to question how memories of dress inform a dialogue between past and present identities. While forgetting is an essential part of memory (Forty 1999) and memories are often considered less secure in older age (Lummis 1987), there seems to be something about memories of dress, and other material things, that persist when other memories are lost. Developing ideas as to why women keep clothes they no longer wear (Banim and Guy 2001; Bye and McKinney 2007; Woodward 2007), I will argue that the materiality of remembered clothing 'wears' in memory and is central to maintaining past identities of the 'woman I was' and the 'woman I wish I could still be' (Slater 2011). ${ }^{1}$

\section{Mary's Dress}

The first garment belonged to Mary who was born in Oldham, Lancashire in 1917. Mary was 92 years old and living in sheltered accommodation with carer support when she recounted the story of her dress in 2009. What stood out about Mary's dress was that she had retained part of the garment.

1 The suggestion that a garment 'wears' in memory is appropriated from the 1919 lyrics of 'Little Alice Blue Gown', a song written by Joseph McCarthy for the musical Irene that was referenced by an interviewee. 
Final Version published as: Slater, A. (2014) 'Wearing in memory-materiality and oral histories of dress', Critical Studies in Fashion and Beauty, Vol. 5, No. 1, pp. 125-139. DOI: 10.1386/csfb.5.1.125_1. (C) Intellect.

In interviews with eleven women and searches through local museum archives, this was the only garment contemporary to the period of my study that was verifiable as 'working-class' dress. Interestingly, Mary's skirt was not kept in a wardrobe, where current clothing tends to be stored or 'rests' when it is not in use (Cwerner 2001). This garment was stored as any other memento might be: safely folded away at the back of a drawer, in a dresser, in her living room.

Mary's story began: 'Well I've got something here ... I saved it'. As she headed across her living room, Mary explained that her brother had paid for the dress with money he had saved from his wages in the Royal Navy. After rummaging through a dresser, Mary found the object of her search, a piece of black silk velvet: 'Oh here we are, it's what they called a dirndl skirt ... it was a dress really and this is the bottom of it'. ${ }^{2}$ Mary explained that 'during the war' she had removed the bodice of the dress, which 'had glass buttons down the front' (Mary 2009 [interview]). The remaining skirt then had rows of shirring elastic sewn in to gather the waistband and the two patch pockets, several inches below the waist, were worn to the front as they had been on the original dress (see Figs. 1-3).

Mary's narrative allows the acquisition of her dress to be dated to before October 1940, when her brother was killed in active service on a submarine in the Royal Navy. She was still wearing the garment as a dress in Christmas 1941, when she met the man whom she went on to marry in early 1942, and in 1943 when she had their first child. ${ }^{3}$ The full length of the skirt seemed to reference the fashionable styles of dresses from the mid-late 1930s, prior to the restrictions on manufacture imposed by the Civilian Clothing 1941 campaign. ${ }^{4}$ However, like many working-class women of this period, Mary had very few clothes and this dress, later a skirt, was worn for many years. Making old

2 A dirndl skirt was made by from a rectangle of material; the short sides were sewn together, the bottom was hemmed and the waistband at the top was gathered using elastic. The term dirndl abbreviates 'Dirndlekleid' meaning a girls' (dirndl) dress (kleid) with a gathered skirt and fitted bodice worn in Bavaria and Austria (Collins 2001 : 413). It is interesting to note that the German term was used to describe these gathered skirts in discussions of clothing at a time when associations with Germany were generally viewed as unpatriotic.

3 Although Mary did not state when the dress was acquired, she revealed enough contextual details to allow for additional research that allowed for this to be accurately dated using online birth and marriage records (Lancashire BMD 2010; Freebmd 2010), cross-referenced with her brother's death entry from the Commonwealth War Graves Commission (2010).

4 A similar dress to that described, and the skirt retained, by Mary is held at the Gallery of Costume (AN: 1995. 175). It is described as a 'black velvet party dress [in rayon velvet] with short sleeves; turn-down pointed front tabs at collar and rolled velvet tie-bow; front band at waist, pointed top and bottom, with 4 horizontal broad bands of sheering above forming front bodice; cb opening at neck with 6 fabric covered buttons; left side placket fastening with 3 hooks and eyes; ties from side seams fastening cb; narrow rolled hem. Unlined'. An image of this 1939 garment is available via Manchester Galleries (2010). 
Final Version published as: Slater, A. (2014) 'Wearing in memory-materiality and oral histories of dress', Critical Studies in Fashion and Beauty, Vol. 5, No. 1, pp. 125-139. DOI: 10.1386/csfb.5.1.125_1. (C) Intellect.

clothes into new garments was a common practice during the war and was promoted as part of the Government's 'Make Do and Mend' campaign from 1942. It may be that Mary's alterations to her garment were inspired by this campaign, although previous research emphasises that, for workingclass women, mending and making do was not a new wartime concept, but a thrift-motivated practice that had been used for decades earlier to prolong the life of a limited wardrobe and gave workingclass women an advantage in needlework skills above their counterparts from higher social groups (Norman 2007; Slater 2010).

[Figures 1, 2 and 3: Available in Printed Version]

\section{Doris' Dress}

The second garment was made by Doris' older sister after clothing rationing had restricted the commercial manufacture of ready-to-wear garments; it was in this context that working-class experiences of home dressmaking came into their own and many girls, like Doris' older sister, utilised their dressmaking skills in their spare time to provide additional clothing for their families (Slater 2010; 2011). Doris was born in Salford in 1921 and at the time of her interview was living in a residential care home in Bolton. Doris was the first to admit that she had a poor memory: she could not remember what year she was born; how old she was; when she married; or when her three sons were born. ${ }^{5}$ Although her confusion was evident in the chronologies of some of her memories, when asked about her favourite item of clothing during the war, Doris clearly recalled the dance dress made for her by her older sister for her 21 st birthday dance, held 'at the chapel up the road' in $1942 .{ }^{6}$ While Mary had retained her 'treasured' dress, Doris regretted not keeping hers:

It was green organdie ... I think you called it then. It was ... a fine material but stiff-ish material ... I think it [had] a round neck and it probably had a bit of trimming on it because she was good at putting the trimming on and then

5 When I first met Doris, the day before her interview, she was waiting at the door of the care home for her late husband to come and take her dancing. As an interviewer, I had significant concerns about the ethics of interviewing someone with such advanced dementia. Yet the care home staff insisted I interviewed Doris as, like many other people with her condition, she loved talking about the past, which offered a more fixed sense of selfidentity than the uncertainties of her present life.

6 Although she could remember that the garment was made for her 21st birthday, Doris was unsure when this was and it was only as a result of the care home providing her date of birth to contextualise her narratives that allowed this garment to be so precisely dated. 
Final Version published as: Slater, A. (2014) 'Wearing in memory-materiality and oral histories of dress', Critical Studies in Fashion and Beauty, Vol. 5, No. 1, pp. 125-139. DOI: 10.1386/csfb.5.1.125_1. (C) Intellect.

there was like a bodice to there [natural waist] and then a very full skirt and each skirt had a pleated frill on about that big [gestures a couple of inches]. And there was about four or five skirts and I was always sorry I got rid of it. I threw it out. But it was a lovely dress and it was green, pale green ... organdie which you know was a stiff-ish material and it went down to my ankles and my sister made me that ... I never forgot that dress because I was always sorry I didn't keep it and the sleeves were all little, three little frills around there [arm hole], pleated frills round there. I remember that very well.

(Doris 2009 [interview])

At several points in her narrative Doris expressed her remorse at not having kept what she considered to be 'a lovely dress'. Doris' account of this dance dress enlivened her interview: she was proud to have once owned this garment and seemed to take a similar stance on the fact that she could remember the garment in such detail. The materiality of the garment is clearly expressed in Doris' account; the light weight and delicate stiffness of the organdie fabric seems to have influenced what made this dress so significant in the landscape of uncertainty, both in memory and physical circumstance, that dominated Doris' present life. When asked what it felt like to wear her green organdie dress, Doris replied 'Oh lovely! [Laughs] You felt like somebody special' (2009 [interview]). As was the case with Mary's black velvet dress/skirt, Doris' dress held a special status both at the time it was first worn and in memory.

\section{Material Meanings}

The materiality of both Mary's and Doris' garments would have stood out in a working-class woman's wardrobe in the late 1930s and early 1940s. The dresses were both constructed in natural fibres, which remained the most commonly used for clothing in this period, despite the increasing development of man-made fibres. However, these silk and cotton fibres are transformed through their specific construction and, as a result, they acquire new meanings (Andrew 2008). As Ingold (2007: 15) suggests, 'the properties of materials, in short, are not attributes but histories' and it is therefore important to consider the contexts of these dresses, and in turn what they are made of, in the context of the period when they were first worn.

When woven into a velvet pile, as in Mary's dress, the silk fibre, which 'sensuously caresses the skin' (Woodward 2007: 77), acquires additional meanings than if it were simply plain-woven. In the late 1930s, a silk-velvet dress was expensive and therefore was a significant luxury for a working-class woman at a time when rayon velvets were being mass-produced for much lower cost, making the fabric more accessible (although still a luxury) for those with lower incomes. As Mary explained, had it 
Final Version published as: Slater, A. (2014) 'Wearing in memory-materiality and oral histories of dress', Critical Studies in Fashion and Beauty, Vol. 5, No. 1, pp. 125-139. DOI: 10.1386/csfb.5.1.125_1. () Intellect.

not been for her brother offering to pay for the garment, she would not have been able to afford to be 'treated' to such an item. The soft fluidity of velvet had long been associated with couture fashion and home interiors and became more associated with sensuality in the pre-war years as the sumptuous pile provided physical and psychological warmth (Lutz 1994).

Mary's garment demonstrates what Ingold (2007: 7) described as the 'flux' state of materials; her dress (now a skirt) remains in its physical state as a material 'object', yet the materiality of the garment has changed. As Woodward (2007: 78) explained, garments worn over time 'age with the wearer, becoming like a second skin'. These traces of wear have an impact on the materiality of a garment, as demonstrated by the rips, tears and faded compression of the velvet pile in Mary's skirt (see Figs. 13 ), a process of decay has begun and, without conservation work, it will eventually decompose.

Doris' dress however remains more fixed in immaterial forms. It no longer exists in its primary physical guise, but secondary traces remain: in her memories and in my recordings and interpretations of her memories. The absence of the physical garment seemed to strengthen her need to remember its materiality. The cotton organdie in Doris' dress also takes on a different meaning in its historical context. As a dress fabric, cotton organdie also has a long history and tends to be associated with wealthy consumers; since the early $19^{\text {th }}$ century cotton lawn had been popular for day and evening wear. When treated with acid, this fine and delicate fabric took on additional qualities; as Doris explained, the cotton organdie's drape and handle stand out from other cotton fabrics through its sheer, delicate stiffness.

Significantly, the materiality of Mary's silk-velvet dress and Doris' cotton organdie dress stand out as working-class woman's wartime attire. These dresses used expensive fabrics that were not traditionally used for working-class dress; although neither woman discussed where the garment/materials had come from, had it not been for Mary's brother's financial support or Doris' sister's dressmaking skills it is likely that neither would have owned such a garment in that period. It might seem unusual that garments for special occasions were even considered at a time collectively remembered for making do, but my research showed that among working-class women, the purchase or home-making of 'best' clothing was prioritised over that of everyday wear. Achieving the 'best' identity that one could portray in public was more important than the reality of a working-class family's material circumstance; after a period of six months or a year, the previous best clothing would then be passed down to everyday wear (Slater 2011). This process may explain why Mary kept the practical black skirt from her velvet dress, which would be suitable for a range of occasions, while Doris discarded her green cotton organdie dress, which would be considered unsuitable attire for workingclass day wear.

Both Mary and Doris' dresses were significant for the wearers at the time they were first worn and, as such, stood out in a lifetime of clothing memories. The fixed names of the fabrics used to construct these garments (velvet and organdie) implies specific material properties and qualities, but a consideration of materiality reinforces what Ingold termed the 'flux' of materials over the lifetime of the garments. Not only would the velvet pile soften with wear, but without careful (and expensive) 
Final Version published as: Slater, A. (2014) 'Wearing in memory-materiality and oral histories of dress', Critical Studies in Fashion and Beauty, Vol. 5, No. 1, pp. 125-139. DOI: 10.1386/csfb.5.1.125_1. (c) Intellect.

laundering so would the delicate crispness of the cotton organdie. These garments show that materiality has different meanings in different contexts and the 'essence' of what made a garment special when it was first worn, may be the same or different from what eventually deemed it suitable or unsuitable for future use. However, the fact that these women kept their garments, whether as a physical material object or as an immaterial memory of a material object, indicates that these dresses held a special status in Mary and Doris' lives.

\section{Material Identities}

The physical retention of clothing, that no longer had an 'active' role in the life of the woman who once wore them, is influenced by the relationship between the clothing and the wearer. Mary and Doris seemed to have recollected these specific garments for similar reasons as to why women keep clothing, as examined by Banim and Guy (2001) and Woodward (2007) who explored women's identities through the meaning they attached to clothes. Banim and Guy suggested three reasons why clothing is kept when it is no longer worn, because it represents: 'the woman I want to be', 'the woman I fear I could be' or 'the woman I am most of the time' (2001: 204). At first, they assumed that clothing was kept purely as a 'memory jogger', to remind the wearer of past events and the original context in which the garment was worn. However, this assumption was revised to consider the theory that retained clothing was not only symbolic according to the memory associated with a garment, but more importantly, it embodied the relationship between the wearer and others (Banim and Guy 2001; Woodward 2007). In this sense, recollections of clothing worn for specific occasions, or associated with a specific person or event, seem to have been as distinctive as the retention of garments found by Banim and Guy. Mary and Doris' reportage of their dresses was also linked to their feelings of selfidentity at the time these specific garments were worn. Just as Banim and Guy (2001: 218) recognised that kept clothing was part of an individual's identity rather than being 'superfluous props', recollected experiences of 'treasured' garments are associated with identity and deeply embedded in the wearer's relationship with other people.

Mary's retained dress served as an embodiment of her 'past' self in her present life (Woodward 2007: 6). Keeping her skirt was one way that Mary could 'negotiate' her place in the world and the physical retention of the object, plus any subsequent viewings, re-connected the skirt with people and places she had experienced wearing it (following Jones 2010). In addition to its tangible connection with her late brother, Mary remembered wearing her velvet dress while helping with a Christmas supper at the local Methodist Sunday School; it was here while wearing her dress that her relationship with the man who would become her husband began:

Why I treasure it as well. I'd got a friend who, he came to be my husband and I had it on one Christmas ... I was helping with the children and the 
Final Version published as: Slater, A. (2014) 'Wearing in memory-materiality and oral histories of dress', Critical Studies in Fashion and Beauty, Vol. 5, No. 1, pp. 125-139. DOI: 10.1386/csfb.5.1.125_1. (C) Intellect.

Christmas supper and [a few years later] when we had our daughter he said 'hurry up home' and 'I can see a girl in a black velvet dress and hurry up home with our baby'. And you know ... that's how he noticed me in that dress that my brother had bought me ... I think that [the dress] took his eye, not me, aye! [Laughs].

(Mary 2009 [interview])

Mary 'treasured' her dress because it embodied her relationships with her late brother, who had paid for the dress, and her late husband, who remembered her wearing it when they first met. The garment held dual significance and by connecting with the materiality of this piece of velvet, through physical touch, Mary seemed to feel closer to both men and the woman she was when these men were a physical part of her everyday life. Developing Banim and Guy's (2001) findings, this garment represented the woman that Mary felt 'she had once been'. This nostalgic association with her past self may also be interpreted in the present as 'the woman I want to be' (Banim and Guy 2001: 204), or 'the woman I wish I could still be': the young woman wearing a black velvet dress with whom the man who would become her husband fell in love, rather than a widow in her nineties, recollecting her experiences for a younger interviewer. Mary's account supports Elizabeth Bye and Ellen McKinney's (2007: 484-485) suggestion that 'sentimental or emotional reasons' and 'personal connections to the clothing or the bodies that once wore them' are central to the conscious decision in retaining a particular garment and, developing this theory, in retaining the memories of the garment. Despite the immateriality of her garment, Doris' memories of her green organdie dress, and its connotations with her sister making clothes for the family, served a similar purpose in embodying her past in her present circumstance as Mary's retention of her black velvet skirt.

The materiality of Mary and Doris' dresses is also significant in the context of their wider wartime experiences and sense of self-identity when these garments were first worn. As previously discussed, these materials were generally considered impractical at a time when the emphasis was on purchasing and making garments that would stand the test of time. But it was also a period when, among lower social groups, dressing up was an important part of boosting public morale, particularly for younger women. In this context, these garments were one of Mary and Doris' final items of selfindulgence prior to their marriages after which, their role as working-class mothers in what Carl Chinn (1988) termed 'the Hidden Matriarchy' meant that, clothing their children became their main sartorial priority. This changing status helps to explain the significance of materiality in these dresses; these two young women's dresses represented that once youthful self, without parental responsibility. As Siân Jones (2010: 190) asserts the materiality of objects embodies the past experiences and relationships that they have been part of' and as a result objects offer some kind of connection to their past lives; this embodiment can equally be applied to the object's owner's past life. Few married working-class women in wartime Britain had the luxury of owning a silk-velvet or cotton-organdie dress 
Final Version published as: Slater, A. (2014) 'Wearing in memory-materiality and oral histories of dress', Critical Studies in Fashion and Beauty, Vol. 5, No. 1, pp. 125-139. DOI: 10.1386/csfb.5.1.125_1. (C) Intellect.

and as a result these garments stood out from other garments worn by Mary and Doris in this period; they also stood out in their memories at the times their stories were recorded.

\section{Material Memories}

The autobiographical memories discussed here relate to personally experienced events or episodes remembered in relation to personal circumstance; they form part of episodic memory, a process that 'begins with the witnessing or experiencing of an event or episode and ends with its subjective remembering' (Tulving 1983: 11). Episodic memory forms part of declarative memory, which is the conscious remembering of previously stored information (Tulving 1983; Coser 1992; Cubitt 2007). The contextualisation of a declarative memory assists in successful storage and retrieval, although episodic memories are vulnerable to interference (Tulving 1983). ${ }^{7}$ Psychologists accept that autobiographical memories 'serve as a basis for an individual's life story' (Paller et al. 2009: 187), but culture also plays an important role in the accessibility and mediation of personal memories (Sangster 1994; Ross and Wang 2010).

In autobiographical memory, exceptional or extra-ordinary events tend to be clearer, more detailed and described more fluidly than those that are less distinctive; this helps explain why dress that was special at the time of wearing stands out in memory. Some recollections, particularly of traumatic events where an individual was actually involved, are reported with intense emotion. Although such recollections do not recapture the full intensity of the actual emotions as initially experienced, Trevor Lummis (1987: 118) argues that this reduction in 'emotional intensity' does not reduce the reliability of what is reported as oral evidence. My research findings support this, as emotional intensity seemed to positively correlate with clarity in recall. Mary had tears in her eyes as she described receiving the letter that her brother was 'missing in action', having to tell her parents and how the house was filled with flowers within hours, despite the poverty of the local community (a factor recognised by Chinn 1988: 40). For Mary, whose family like so many others during the Second World War had no body to bury after her brother's death at sea, the retained black velvet skirt came to serve as a memento of her brother's life, and death, and the life of the person she was at the time he died and she first met her husband; it offered a tangible, material link to her past.

7 One example of potential interference is the use of photographs in oral history approaches to the study of dress. It has been suggested that photographs can 'flesh' out memories of dress (Buckley 1998: 164). However, psychological research shows that using photographs to prompt recall can significantly influence what is remembered as photographs produce memory and can serve as 'records' of the past beyond autobiographical memory (Kwint 1999: 2; Edwards 1999; Sturken 1999; Kuhn 2002; Garry and Gerrie 2005; Langford 2006). The two garments discussed here were selected to simplify the interpretation of any potential influence of photographs on remembered materiality, as there are no surviving contemporary photographs of the garments and neither interviewee reported having one. 
Final Version published as: Slater, A. (2014) 'Wearing in memory-materiality and oral histories of dress', Critical Studies in Fashion and Beauty, Vol. 5, No. 1, pp. 125-139. DOI: 10.1386/csfb.5.1.125_1. (C) Intellect.

Throughout her interview Doris returned to the story of her green dress and reflected on her memories of 'that dress: that was in my memory because it was a lovely dress'; 'I was always sorry I got rid of it. I threw it out ... I never forgot that dress because I was always sorry I didn't keep it'; 'I'm always sorry I didn't save ... it, but you never did in those days, you just wore 'em' (Doris 2009 [interview, original verbal emphasis]). It is likely that Doris' repetitive accounts of this garment served to fill in, or as Martha Langford (2006: 225) termed it 'camouflage', the gaps of her autobiographical memory. Yet, in the same way as other interviewees treasured photographs of their favourite garments, it seems that Doris' conscious remembering of her dance dress was emphasised because her memory of the now immaterial garment retained something, if only a revisionist fragment, of the original dress. In other words, because Doris had not kept this garment, she may have had a greater sense of responsibility to remember it (following Poole 2008) and share her memories of its materiality.

Mary and Doris articulated the potential fallibility of their memories in some areas, but they seemed to consider the remembered materiality of clothing as a signifier of authenticity. While the workings of human memory are not fully understood and there is no way to determine the absolute truth of a single memory, ${ }^{8}$ psychological research into memory and reliability offers some explanation as to why autobiographical memories of materiality can seem particularly veracious. For example, Ken Paller, Joel Voss and Carmen Westernberg (2009: 197) suggest that more reliable memories 'might include ... information about multiple sensory modalities' and Daniel Bernstein and Elizabeth Loftus (2009) acknowledge that 'true memory' tends to contain more detailed evidence of personal experience: 'especially sensory detail like sight, sound, touch, taste, and smell ... [and] visual, auditory, and olfactory details' (Bernstein and Loftus 2009: 372-373). The 'multiple sensory modalities' though which we experience dress might explain why the persistence of material memories are strong and persuasive and strengthens belief in what is recalled.

Recollections of materiality also seem to help to validate an individual within their current setting, by perpetuating a tangible, sensory link with the identities of their former selves. It is notable that both Mary and Doris framed their recollections around memories of dresses that represented the independent young women that they had once been. Their narratives, assisted in Mary's case by the physical retention of the garment and the much-regretted loss of it in Doris' case, highlight that garments that were considered to present a particular identity at the time they were first worn also played a significant role in later remembrance. The interviewees remembered their clothes according

8 Cognitive psychologists have considered the reliability of the memories that are reported, while law enforcement tends to focus on trustworthiness of the person reporting the memories. However, as Bernstein and Loftus (2009: 370) recognise, 'neither approach presently can' determine absolute truth and to their knowledge, 'nobody has developed a neurophysiological procedure that can be used to predict whether a single memory is true or false' (Bernstein and Loftus 2009: 371). As a result, Lummis' (1987: 117) suggestion that 'the careful historical evaluation of the information itself is probably as sound as anything that can be offered by psychologists' remains the best advice for an oral historian today. 
Final Version published as: Slater, A. (2014) 'Wearing in memory-materiality and oral histories of dress', Critical Studies in Fashion and Beauty, Vol. 5, No. 1, pp. 125-139. DOI: 10.1386/csfb.5.1.125_1. (C) Intellect.

to their re-construction of the identity of their former selves, set against their feelings of self-identity at the time of interview. Their sensory and experiential memories of these specific garments appeared to have played a significant role in accepting the difficulties of their current situations. The remembered materiality of a garment, whether that garment is material or immaterial in the present, seems to serve as a 'talisman' between past and present.

\section{Conclusion}

Changes in lifestyle and identities, whether chosen, imposed or a result of ageing, are reflected in our memories of dress. The temporalities of dress, in terms of fashionable styles or new materials, or achieving 'the look' desired at a particular moment, are remembered in more detail. However, clothing memories are significantly shaped by our sense of self-identity and our relationships with others at the time a garment was first worn. The materiality of dress connects us to the very essence of what it means to have an embodied experience with clothes.

Sometimes a garment is retained and its materiality survives. Yet its materiality is not fixed; it ages and, as with personal identity, changes over time (following Ingold 2007). In other circumstances, a garment has been discarded and its materiality is sustained and endured only in memory. Yet this remembered materiality is strong and persuasive. The remembered materiality of clothing feels as real to the wearer as the physical material garment; materiality persists in memory long after the garment's material life and is central to the past, current and future identities of the wearer.

Moreover, the sensory effects and tactility of clothing memories are considered signifiers of true memory (Paller et al. 2009; Bernstein and Loftus 2009). When we remember the appearance of clothing and how items were worn with each other and functioned as worn objects, for example as shown in a photograph, it may be unclear if we remember the garment or the representation, or even a story that we have been told relating to that garment by someone else who was present at the time. However, if we remember the garment's materiality: its feel, its fabric, its smell, its texture, why it was bought, the different occasions when it was worn and moreover what it felt like to wear and what we (the sense of self in the past) felt like wearing it, then we can be more confident that we remember the physical garment in the wider context of how it was experienced. The materiality of dress 'wears' in memory, regardless of whether the garment itself remains material or is now immaterial; it plays a significant role at the time of wearing, in memory formation and in how garments 'wear' in our longterm memories.

\section{References}

Andrew, Sonja (2008) 'Textile Semantics: Considering a Communication-based Reading of Textiles' in Textile: The Journal of Cloth and Culture, Vol. 6, No. 1, pp. 32-65. 
Final Version published as: Slater, A. (2014) 'Wearing in memory-materiality and oral histories of dress', Critical Studies in Fashion and Beauty, Vol. 5, No. 1, pp. 125-139. DOI: 10.1386/csfb.5.1.125_1. (c) Intellect.

Banim, Maura and Guy, Ali (2001) 'Dis/continued Selves: Why Do Women Keep Clothes They No Longer Wear?' in A. Guy, E. Green and M. Banim (eds) Through the Wardrobe: Women's Relationships with Their Clothes, Oxford: Berg, pp. 203-220.

Bernstein, Daniel M. and Loftus, Elizabeth F. (2009) 'How to Tell if a Particular Memory is True or False' in Perspectives on Psychological Science, Vol. 4, July 2009, pp. 370-374.

Bye, Elizabeth and McKinney, Ellen (2007) 'Sizing up the Wardrobe - Why We Keep Clothes That Do Not Fit' in Fashion Theory: The Journal of Dress, Body and Culture, Vol. 11, No. 4, pp. 483-498.

Chinn, Carl (1988) They Worked All Their Lives: Women of the Urban Poor in England, 1880-1939, Manchester; Manchester University Press.

Collins (2001) Concise Dictionary: 21st Century Edition, Glasgow: HarperCollins [1982].

Commonwealth War Graves Commission (2010) Search for 'Find War Dead'. http://www.cwgc.org/findwar-dead.aspx. Accessed 20 December 2013.

Coser, Lewis (1992) (ed. and trans.) Maurice Halbwachs: On Collective Memory, Chicago, Illinois: University of Chicago Press.

Cubitt, Geoffrey (2007) History and Memory, Manchester: Manchester University Press.

Cwerner, Saulo B. (2001) 'Clothes at Rest: Elements for a Sociology of the Wardrobe' in Fashion Theory: The Journal of Dress, Body and Culture, Vol. 5, No. 1, February 2001, pp. 79-92.

Doris (2009) Interviewed by Author, 29 October 2009.

Edwards, Elizabeth (1999) 'Photographs as Objects of Memory' in M. Kwint, C. Breward and J. Aynsley (eds) Material Memories, Oxford: Berg, pp. 221-236.

Freebmd (2010) 'Search for Births, Marriages and Deaths'. http://freebmd.org.uk/cgi/search.pl. Accessed 20 December 2013.

Forty, Adrian (1999) 'Introduction' in A. Forty and S. Küchler (eds) The Art of Forgetting, Oxford: Berg. Garry, Marianne and Gerrie, Matthew (2005) 'When Photographs Create False Memories' in Current Directions in Psychological Science, Vol. 14, No. 6, pp. 321-325.

Giddens, Anthony (1991) Modernity and Self-Identity: Self and Society in the Late Modern Age, Stanford, California: Stanford University Press.

Ingold, Tim (2007) 'Materials against Materiality' in Archaeological Dialogues, Vol. 14, No. 1, pp. 1-16. Jones, Siân (2010) 'Negotiating Authentic Objects and Authentic Selves: Beyond the Deconstruction of Authenticity' in Journal of Material Culture, Vol. 15, No. 2, pp. 181-203.

Kuhn, Annette (2002) Family Secrets: Acts of Memory and Imagination, London: Verso [1995].

Kwint, Marius (1999) 'Introduction: The Physical Past' in M. Kwint, C. Breward and J. Aynsley (eds) Material Memories, Oxford: Berg, pp. 1-16.

Lancashire BMD (2010) 'Search for Lancashire Births, Marriages and Deaths'. http://lancashirebmd.org.uk/. Accessed 20 December 2013.

Langford, Martha (2006) 'Speaking the Album: An Application of Oral Photographic Framework' in A. Kuhn and K. M. McAllister (eds) Locating Memory: Photographic Acts, Oxford and New York: Berghahn Books, pp. 223-246.

Lummis, Trevor (1987) Listening to History, London: Century Hutchinson.

Lutz, Hazel (1994) 'From Wealth to Sensuality: The Changing Meaning of Velvet 1910-1939' in M. Revell Delong and A. M. Fiore (eds) Aesthetics of Textiles and Clothing: Advancing Multi-Disciplinary Perspectives, Special Publication 7, Monument, Colorado: International Textile and Apparel Association, pp. 105-119.

McCarthy, Joseph (1919) 'Little Alice Blue Gown’ song lyrics from the musical Irene. 
Final Version published as: Slater, A. (2014) 'Wearing in memory-materiality and oral histories of dress', Critical Studies in Fashion and Beauty, Vol. 5, No. 1, pp. 125-139. DOI: 10.1386/csfb.5.1.125_1. (c) Intellect.

Manchester Galleries (2010) 'Search the collection', including the Gallery of Costume held at Platt Hall. http://www.manchestergalleries.org/the-collections/search-the-collection/. Accessed 20

December 2013.

Mary (2009) Interviewed by Author, 30 April 2009.

Norman, Jill (2007) 'Foreword' in (ed.), Make Do and Mend: Keeping Family and Home Afloat on War Rations, London: Michael O'Mara Books, pp. 5-12.

Norris, Lucy (2005) 'Cloth That Lies: The Secrets of Recycling in India' in S. Küchler and D. Miller (eds) Clothing as Material Culture, Oxford: Berg, pp. 83-105.

OED (2014) 'Materiality' in Oxford English Dictionary. http://www.oed.com. Accessed 28 April 2014.

Paller, Ken A., Voss, Joel L. and Westernberg, Carmen E. (2009) 'Investigating the Awareness of Remembering' in Perspectives on Psychological Science, Vol. 4, pp. 185-199.

Poole, Ross (2008) 'Memory, history and the claims of the past' in Memory Studies, Vol. 1, pp. 149166.

Pye, David (1995) The nature and art of workmanship, London: The Herbert Press. $1^{\text {st }}$ Ed. 1968, Cambridge University Press.

Sturken, Marita (1999) 'The Image as Memorial: Personal Photographs in Cultural Memory' in M. Hirsch (ed.), The Familiar Gaze, Hannover, New Hampshire: University Press of New England, pp. 178-195.

Slater, Alison (2010) 'Make-do-and-Mend: 'Leisure' or 'Work' in the Lives of Working-Class Women in Bolton and Oldham, Lancashire 1939-1945?' in R. Snape and H. Pussard (eds) Recording Leisure Lives: Sports, Games and Pastimes in $20^{\text {th }}$ Century Britain, Eastbourne: Leisure Studies Association, pp. 41-55.

Slater, Alison (2011) 'The Dress of Working-Class Women in Bolton and Oldham, Lancashire 1939 to 1945', Ph.D. thesis, Manchester: Manchester Metropolitan University.

Taylor, Lou (2002) The Study of Dress History, Manchester: Manchester University Press.

Tulving, Endel (1983) Elements in Episodic Memory, Oxford: Claredon Press.

Weiner, Annette and Schneider, Jane (1989) Cloth and the Human Experience, London: Smithsonian Institute Press.

Woodward, Sophie (2002) 'Review Article: Making Fashion Material' in Journal of Material Culture, Vol. 7, No. 3, pp. 345-353.

Woodward, Sophie (2007) Why Women Wear What They Wear, Oxford: Berg.

\section{Author's Biography}

Dr Alison Slater is a Lecturer in Design History at Manchester School of Art, Manchester Metropolitan University. Her research explores the relationship between designed objects, particularly dress, memories and histories. The primary research discussed here was gathered during her doctoral research and funded by the Arts and Humanities Research Council.

\section{Contact Details}

Dr Alison Slater, Room G15, Grosvenor Building, Manchester School of Art, Manchester Metropolitan University, Cavendish Street, Manchester, M15 6BR; a.slater@mmu.ac.uk; 01612471291. 